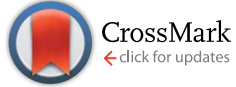

Cite this: RSC Adv., 2017, 7, 16997

Received 24th January 2017

Accepted 12th March 2017

DOI: 10.1039/c7ra01059a

rsc.li/rsc-advances

\section{Purification of antibiotics from the millet extract using hybrid molecularly imprinted polymers based on deep eutectic solvents}

\begin{abstract}
Xiaoxia Li and Kyung Ho Row*
Deep eutectic solvents (DESs) are potential ecofriendly surfactants for the preparation of various materials. In this study, molecularly imprinted polymers (MIPs) were modified by betaine-based DESs. These materials were characterized by field emission scanning electron microscope and Fourier transform infrared spectroscopy. The molecular recognition capability for antibiotics of materials was evaluated by static absorption and dynamic adsorption curves. Five materials were used as solid phase extraction (SPE) adsorbents for the rapid purification of levofloxacin and tetracycline from the millet extract. The DES-based materials showed more selective adsorption than the conventional MIPs. The adsorption curves of DES-MIP showed superior molecular recognition ability and binding capability for antibiotics than the other materials. The limit of detection and the limit of quantitation of the method for levofloxacin were $0.01 \mu \mathrm{g} \mathrm{mL}^{-1}$ and $0.03 \mu \mathrm{g} \mathrm{mL}^{-1}$, respectively. The method recoveries ranged from $97.2-100.2 \%$ for levofloxacin with DES-LMIP and $95.7-99.2 \%$ for tetracycline with DES-TMIP. DES-LMIP and DES-TMIP showed the highest selectivity recovery for levofloxacin (94.5\%) and tetracycline $(93.3 \%)$ from millet extract with mixture antibiotics, and could remove the interferent effectively.
\end{abstract}

\section{Introduction}

Deep eutectic solvents (DESs) have attracted considerable attention as a new type of eco-friendly solvent for many technologies in chemistry since their discovery by Abbott et al. in $2003 .^{1-4}$ DESs are a type of eco-friendly designer solvent composed of a hydrogen bond donor (HBD) and a hydrogenbond acceptor (HBA) compound. ${ }^{5}$ The most common HBA of DES is choline chloride $(\mathrm{ChCl})$. On the other hand, $\mathrm{ChCl}$ is relatively expensive. Therefore, to expand the applications of DES, it is important to search for inexpensive and easily accessible HBA as alternatives to $\mathrm{ChCl}$. In this context, betaine was chosen as a substitute.

In recent years, antibiotics have been applied increasingly to humans and animals. Large numbers of antibiotics are used as immunosuppressive agents, antitumor agents, enzyme inhibitors, hypocholesterolemic agents, antiparasitic agents, and antimigraine agents. Therefore, antibiotics are released into natural ecosystems in large amounts. ${ }^{6}$ In addition, the decomposition period in the environment of most antibiotics is relatively long, meaning that some antibiotics can remain in various environmental water systems. The antibiotic vestigital is absorbed by human body from drinking water and food. ${ }^{7,8}$

Department of Chemistry and Chemical Engineering, Inha University, Incheon 402-751, Korea. E-mail: rowkho@inha.ac.kr; Fax: +82-32-872-0959; Tel: +82-32$860-7470$
Those antibiotic vestigital have adverse effects on human health, such as reactions in sensitive individuals. ${ }^{\mathbf{9}, 10}$ Therefore, the elimination of antibiotics from the environment is essential. Levofloxacin and tetracycline are very common antibiotics in human life and they have been detected frequently in several environmental water systems. ${ }^{11,12}$ Millet is one of the most common cereal crops. As a common food, millet contains a variety of compounds beneficial to human health. Millet congee can be used for the analysis of antibiotics in natural systems.

Currently, a variety of chromatographic methods have been developed for the analysis of antibiotics. ${ }^{13-15}$ Sample pretreatment is an essential step for improving the test results. SPE is currently one of the most widely used techniques for extracting compounds from mixture samples. ${ }^{\mathbf{1 6 , 1 7}}$ On the other hand, it is very important to select a suitable sorbent for SPE to control the parameters, such as selectivity, affinity, and capacity. ${ }^{\mathbf{1 8 - 2 1}}$

Molecularly imprinted polymers (MIPs) exhibiting high selectivity and affinity to a predetermined molecule (template) have attracted increasing interest. ${ }^{22,23}$ In recent years, hybrid functional monomers (3-aminopropyltriethoxysilane-methacrylic acid (APTES-MAA)) have been applied widely to the preparation of MIPs. ${ }^{\mathbf{2 4 , 2 5}}$ Hybrid MIPs offer high permeability, excellent mechanical strength, and good organic solvent tolerance. The selectivity of MIPs to a template is closely related to the template structure. ${ }^{26-28}$ MIP is a promising sorbent owing to 
its novel structure, which combines a uniformly ordered structure, high pore volume, and high surface area. ${ }^{29}$ DESs were introduced in the synthesis of MIPs to improve the affinity and selectivity of MIPs. ${ }^{30}$

In this study, certain amounts of levofloxacin and tetracycline were added to the millet extract. The mixed aqueous solution was used in the analysis to simulate a natural system. In order to significantly increase the concentration of the sample and eliminate interfering compounds, SPE had been applied as a preconcentration step. The DES (synthesized with betaine and ethylene glycol)-modified MIP (DES-LMIP and DES-TMIP), LMIP (without DES), TMIP and NIP (without template and DES) were obtained using an identical procedure. After synthesis, the obtained materials were characterized by scanning electron microscopy (SEM) and Fourier transform infrared (FT-IR) spectroscopy. All the materials were applied to rapid purification of extracts as the SPE adsorbent.

\section{Experimental}

\subsection{Chemicals and reagents}

Levofloxacin $(>98.0 \%)$, tetracycline $(>98.0 \%)$, betaine $(>98.0 \%)$ and were supplied by Tokyo Chemical Industry Co. Ltd. (Tokyo, Japan). 3-Aminopropyltriethoxysilane (APTES 99\%) and 2,2azobisisobutyronitrile (AIBN 98\%) were supplied by Duksan Pure Chemicals Co., Ltd. (Ansan, Korea). Methacrylic acid (MAA 98\%), ethylene glycoldimethacrylate (EGDMA 98\%), methanol (>99.9\%), ethanol (>99.9\%), acetonitrile (>99.9\%), tetraethoxysilane (TEOS, 98\%) and ethylene glycol (>99.5\%) were acquired from Alfa Aesar (Heysham, England). Hydrochloric acid ( $\mathrm{HCl}$, $36 \%$ ) were supplied by Kosdaq Co., Ltd. (Siheung, Korean). All other inorganic reagents and organic solvents were procured from Duksan Pure Chemicals Co., Ltd. (Ansan, Korea). Distilled water was filtered using a vacuum pump and filter (HA-0.45, both from Millipore, USA) prior to apply. All targets were filtered (MFS-25, $0.2 \mu \mathrm{m}$ TF, Whatman, USA) before being injected into the high performance liquid chromatography (HPLC) system.

\subsection{Instrumentation and conditions}

FT-IR spectroscopy (Perkin Elmer, USA) was used to examine the functional groups of the five test materials using a pressed $\mathrm{KBr}$ pellet method in the range, $400-4000 \mathrm{~cm}^{-1}$. The morphological evaluation was carried out by field emission-SEM (FE-SEM, S4200, Hitachi, Ontario, Canada). HPLC analysis was performed using a Younglin HPLC system equipped with a UV Detector (Younglin, Korea) and an M930 solvent delivery pump (Younglin, Korea). The analytical column $(150 \mathrm{~mm} \times 4.6 \mathrm{~mm}$ I.D., $\left.\mathrm{C}_{18}, 5.0 \mu \mathrm{m}\right)$ was acquired from RStech. Co., Korea. The mobile phase was $0.05 \mathrm{M} \mathrm{NaH}_{2} \mathrm{PO}_{4}-\mathrm{ACN}(82: 18 \mathrm{v} / \mathrm{v} \mathrm{pH}=3)$

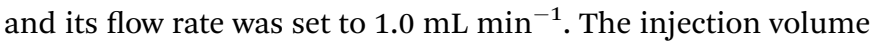
was $10 \mu \mathrm{L}$ and detection wavelength of UV detector was set to $294 \mathrm{~nm}$.

\subsection{Preparation of DESs}

In this study, betaine-based DESs were synthesized using a heating method. The eutectic mixtures (ratio $1: 2: 1$ ) consisting of a HBA (betaine), HBD (ethylene glycol), and water were stirred at $80^{\circ} \mathrm{C}$ (Fig. 1) until an even, colorless liquid had formed.

\subsection{Synthesis of the polymers based on DESs}

Table 1 and Fig. 2 present the scheme for MIPs preparation. First of all, $6.4 \mathrm{mmol}$ APTES and $8.1 \mathrm{mmol}$ MAA were mixed at $60^{\circ} \mathrm{C}$ for $24 \mathrm{~h}$ to prepare the monomer APTES-MAA. Subsequently, the template (levofloxacin or tetracycline, $1 \mathrm{mmol}$ ) and $3.3 \mathrm{mmol}$ APTES-MAA were added to $12 \mathrm{~mL}$ of methanol, and the mixtures were sonicated for $10 \mathrm{~min}$ until they were fully dissolved; they were then stored at $4{ }^{\circ} \mathrm{C}$ in the dark for $1 \mathrm{~h}$. A $1.0 \mathrm{~mL}$ sample of TEOS after alcoholysis, $0.3 \mathrm{mmol}$ AIBN and $25 \mathrm{mmol}$ EGDMA were then added to the solution. Subsequently, $1.5 \mathrm{mmol}$ betaine-based DES was then added (conventional MIPs do not require this step). After deoxygenating the solution with bubbling nitrogen for $10 \mathrm{~min}$, the mixture was synthesized at $60{ }^{\circ} \mathrm{C}$ for $24 \mathrm{~h}$. After polymerization, the resulting bulk materials were ground and sieved with a 0.054 $\mathrm{mm}$ aperture sieve, and the smallest particles of polymers were separated by sedimentation in acetone. The materials were washed successively in a Soxhlet apparatus with $\mathrm{MeOH}$ and

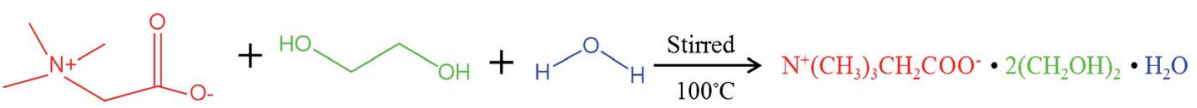

Fig. 1 Preparation of based-betaine DES

Table 1 Specific information of the preparation of the proposed materials

\begin{tabular}{|c|c|c|c|c|c|}
\hline Formulation & NIP & MIP & DES-MIP & MIP & DES-MIP \\
\hline Monomer (APTES-MAA) & $3.3 \mathrm{mmol}$ & $3.3 \mathrm{mmol}$ & $3.3 \mathrm{mmol}$ & $3.3 \mathrm{mmol}$ & $3.3 \mathrm{mmol}$ \\
\hline Crosslinking agent (EGDMA) & $25 \mathrm{mmol}$ & $25 \mathrm{mmol}$ & $25 \mathrm{mmol}$ & $25 \mathrm{mmol}$ & $25 \mathrm{mmol}$ \\
\hline TEOS & $1 \mathrm{~mL}$ & $1 \mathrm{~mL}$ & $1 \mathrm{~mL}$ & $1 \mathrm{~mL}$ & $1 \mathrm{~mL}$ \\
\hline DES & - & - & $15 \mathrm{mmol}$ & - & $15 \mathrm{mmol}$ \\
\hline Template & - & $\begin{array}{l}\text { Levofloxacin, } \\
1 \mathrm{mmol}\end{array}$ & $\begin{array}{l}\text { Levofloxacin, } \\
1 \mathrm{mmol}\end{array}$ & $\begin{array}{l}\text { Tetracycline, } \\
1 \mathrm{mmol}\end{array}$ & $\begin{array}{l}\text { Tetracycline, } \\
1 \mathrm{mmol}\end{array}$ \\
\hline
\end{tabular}



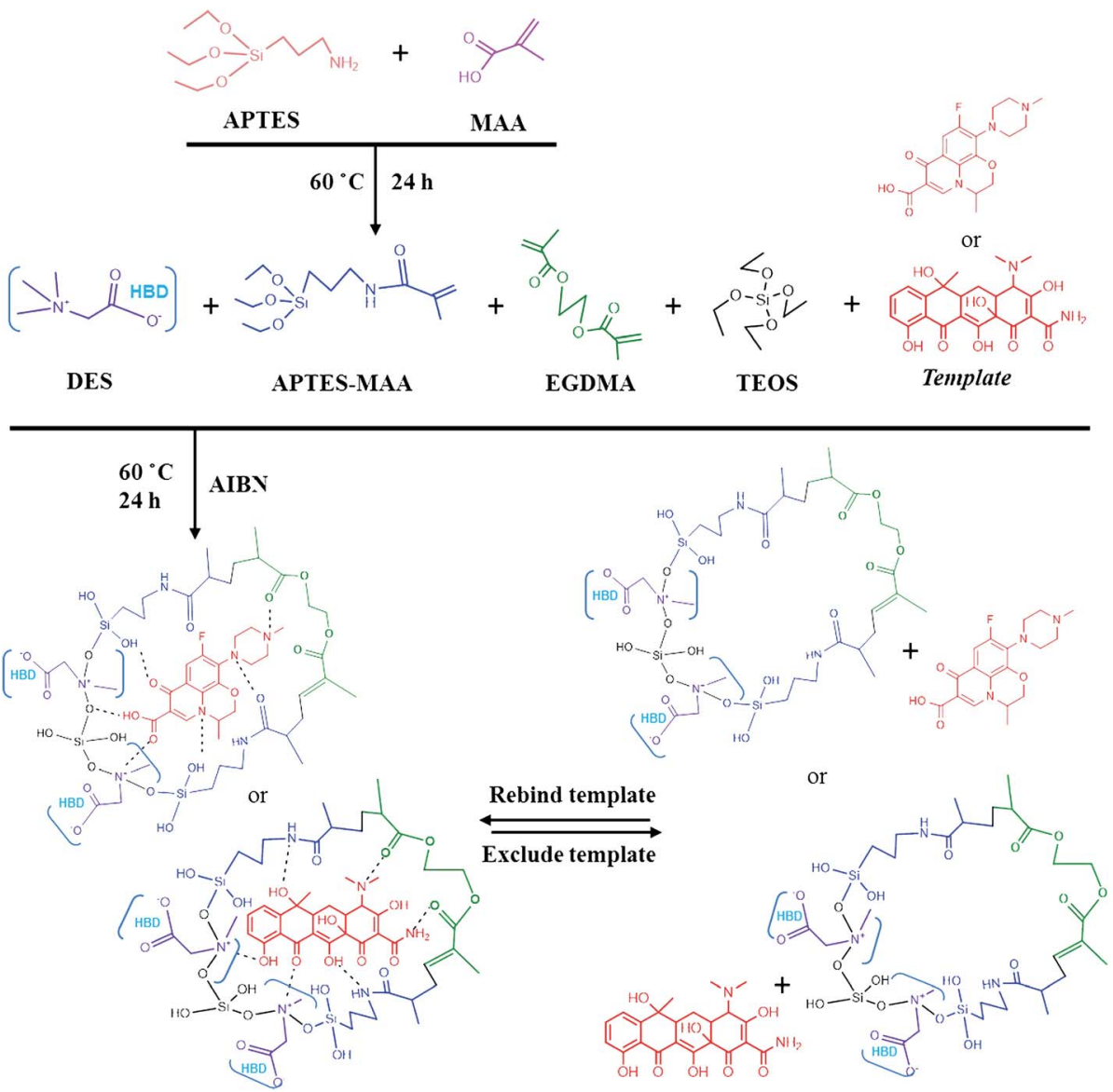

Fig. 2 Schematic illustration of the proposed materials formation.

$\mathrm{MeOH}-\mathrm{HAc}(9: 1, \mathrm{v} / \mathrm{v})$ for $24 \mathrm{~h}$ to remove the template, and dried under reduced pressure. The efficiency of this procedure was checked by HPLC. The non-imprinted polymers (NIPs prepared without template) were synthesized and treated in a same method.

\subsection{Absorption capacity of the materials}

In the static adsorption test, $30 \mathrm{mg}$ of the proposed materials was placed in a tapered plastic centrifuge tube with a stopper containing $10.0 \mathrm{~mL}$ of the $\mathrm{MeOH}$ solutions with levofloxacin (tetracycline) at concentrations of $5-500 \mu \mathrm{g} \mathrm{mL} \mathrm{m}^{-1}$, respectively. The mixtures were shaken mechanically for $12 \mathrm{~h}$ at room temperature using a horizontal shaker and separated for centrifugation at $6000 \mathrm{rpm}$ for $15 \mathrm{~min}$. The concentration of target in the solution was analyzed by HPLC. In the dynamic adsorption test, the proposed materials were weighed $(30 \mathrm{mg})$ and suspended in 1.0 $\mathrm{mL}$ of a levofloxacin (tetracycline) solution of $50 \mu \mathrm{g} \mathrm{mL} \mathrm{me}^{-1}$. The mixtures were shaken mechanically for $1,2,4,6,8,10$, and $12 \mathrm{~h}$ at room temperature. The proposed materials were used repeatedly in the above experiment. ${ }^{31}$

\subsection{Characterization of the materials}

The morphology of the proposed materials was observed by FESEM. The molecular structure of the proposed materials was examined by FT-IR applying the KBr pellet method. In the FT-IR disk preparation process, $1 \mathrm{mg}$ of the material was ground together with $200 \mathrm{mg}$ of $\mathrm{KBr}$ to produce a pellet; the percentage of sample to $\mathrm{KBr}$ was $0.5 \mathrm{wt} \%$. The FT-IR measurement range was from 4000 to $400 \mathrm{~cm}^{-1}$.

\subsection{Purification of antibiotics from the millet extract}

A $5.0 \mathrm{~g}$ sample of millet was added to $50 \mathrm{~mL}$ of DI-water with stirring at $80{ }^{\circ} \mathrm{C}$ for $1 \mathrm{~h}$. The extraction solution was separated by centrifugation at $6000 \mathrm{rpm}$ for $15 \mathrm{~min}$. The supernatant was cooled to room temperature and filtered through a $0.45 \mu \mathrm{m}$ membrane prior to the SPE procedure. To simulate the natural systems, $500 \mathrm{ng}$ of levofloxacin and tetracycline was added to 10 $\mathrm{mL}$ of a millet extractive (Fig. 3). A $200 \mathrm{mg}$ sample of these materials was packed into five empty SPE cartridges and frits were placed at the lower and upper ends to avoid polymer loss.

The antibiotic sample $(1.0 \mathrm{~mL})$ was loaded into the DES-SPE columns, and washed with DI-water $(1.0 \mathrm{~mL})$. The sample was eluted from the columns applying $\mathrm{MeOH}-\mathrm{HAc}(9: 1, \mathrm{v} / \mathrm{v}, 1.0$ $\mathrm{mL}$ ). The eluted $\mathrm{MeOH}-\mathrm{HAc}$ was collected at a constant volume $(1.0 \mathrm{~mL})$ for further analysis by HPLC.

\section{Results and discussion}

\subsection{Preparation of materials}

Selection of the monomer is a crucial step for the synthesis of a polymer, and APTES-MAA was used in this study as a hybrid 


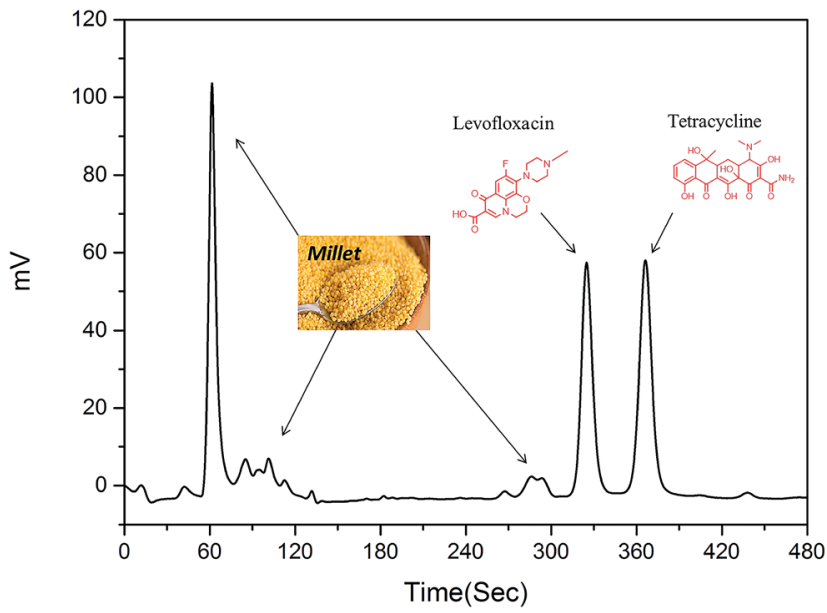

Fig. 3 The chromatogram of millet extractive with levofloxacin and tetracycline $\left(50 \mathrm{ng} \mathrm{mL}^{-1}\right)$. Column: $\mathrm{C} 18(150 \times 4.6 \mathrm{~mm}$ i.d. $)$, detector: UV (294 mm), injection volume: $10 \mu \mathrm{L}$, mobile phase: $0.05 \mathrm{M}$ $\mathrm{NaH}_{2} \mathrm{PO}_{4}-\mathrm{ACN}(82: 18 \mathrm{v} / \mathrm{v} \mathrm{pH}=3)$, flow rate: $1 \mathrm{~mL} \mathrm{~min}$.

functional monomer for the synthesis of MIPs. The APTES and MAA contained different functional groups in their molecules. $\mathrm{C}=\mathrm{C}$ of MAA can be cross-linked with a crosslinking agent by thermal-initiated free radical polymerization in the presence of AIBN, while $-\mathrm{COOH}$ can be the functional group on the surface of material to form a hydrogen bond with a template, and it could also dehydrate with silicon hydroxyl; the silicate ester bond of APTES can release silicon hydroxyl and cause APTES to be embedded firmly in the silica matrix from the condensation of TEOS, while $-\mathrm{NH}_{2}$ could be the functional group on the polymer surface to form a hydrogen bond with the template. Therefore, APTES-MAA was applied as a functional monomer. In this study, both the LMIP and TMIP were modified by DES. In view of a DES composed of a salt with a hydrogen donor, DES has not only hydrophobic and $\pi-\pi$ interactions with the polymer, but also hydrogen-bonding interactions with the $-\mathrm{OH}$ groups of the polymer. Based on the flexible structure of DESs containing both an organic group and an anion, DESs might be a potential surfactant in the preparation of various materials. Many functional groups from DES were observed over the surface of the DES-based materials. DES formed hydrogen bonds with the surface hydroxyl groups of particles. Therefore, the adsorption efficiency might benefit substantially by such particle aggregation. A betaine-based DES was applied successfully to the synthesis of MIPs.

As shown in Fig. 4, these new materials will have different adsorptivity for the standard solution in the SPE procedure. The rate of antibiotics loss using the NIPs adsorbent (without the analyte as a template in synthetic process) was much higher than with the MIPs and DES-MIPs adsorbent. In two of the MIPs, DES-MIPs showed the lowest loss rate, and the loss rate of NIP was higher than that of DES-MIPs and MIPs. Overall, the DES-modified materials showed more selective adsorption than the conventional materials.

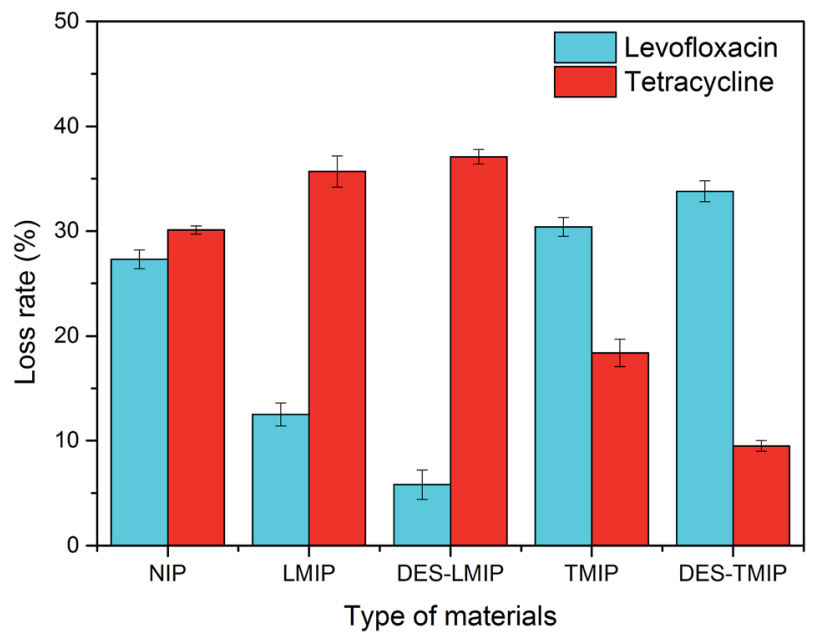

Fig. 4 The loss rates of materials for levofloxacin and tetracycline. Column: C18 $(150 \times 4.6 \mathrm{~mm}$ i.d.), detector: UV $(294 \mathrm{~mm})$, injection volume: $10 \mu \mathrm{L}$, mobile phase: $0.05 \mathrm{M} \mathrm{NaH}_{2} \mathrm{PO}_{4}-\mathrm{ACN}(82: 18 \mathrm{v} / \mathrm{v} \mathrm{pH}=$ 3), flow rate: $1 \mathrm{~mL} \mathrm{~min}^{-1}$.

\subsection{Characteristics of the materials}

Fig. 5 shows FE-SEM images of the five proposed materials; many particles were observed. These materials were not spherical particles, but the structure was similar to a cotton shape. On the other hand, these materials also showed some differences. The mean particle size and surface morphology of these new materials were different. These minor modifications in preparation led to a significant change in particle morphology. Many different small pores and functional groups were formed over the surface of the proposed materials. Therefore, the adsorption capacity and selectivity might benefit substantially from such particle aggregation.

FT-IR spectroscopy is a common technique for investigating the material conformation because it can provide abundant information on the structure. The FT-IR spectra has two regions: functional group region $\left(4000-1330 \mathrm{~cm}^{-1}\right)$ and fingerprint region (1330-400 $\mathrm{cm}^{-1}$ ). As shown in Fig. 6, all of these materials had a similar fingerprint region because they were the same type of materials. The functional group region showed a small difference between the traditional materials and DES-based materials, because betaine-based DES had been applied to the synthesis of the materials. Fig. 6 shows same different functional group peaks between these five proposed materials. The $\mathrm{N}-\mathrm{H}\left(3500-3300 \mathrm{~cm}^{-1}\right)$ peak on these four MIPs (LMIP, DES-LMIP, TMIP and DES-TMIP) was much more remarkable than it on NIP. The reason for this difference is that the template was added to the synthesis process of MIPs. On the other hand, Fig. 6 shows functional group peaks at $1550 \mathrm{~cm}^{-1}$ and $2350 \mathrm{~cm}^{-1}$ in FT-IR spectra of the DES-based MIPs. These functional groups should be based on the modification of betaine-based DES. Betaine-based DES was connected to the surface of these materials. Therefore, these materials had been modified by betaine-based DES successfully. 


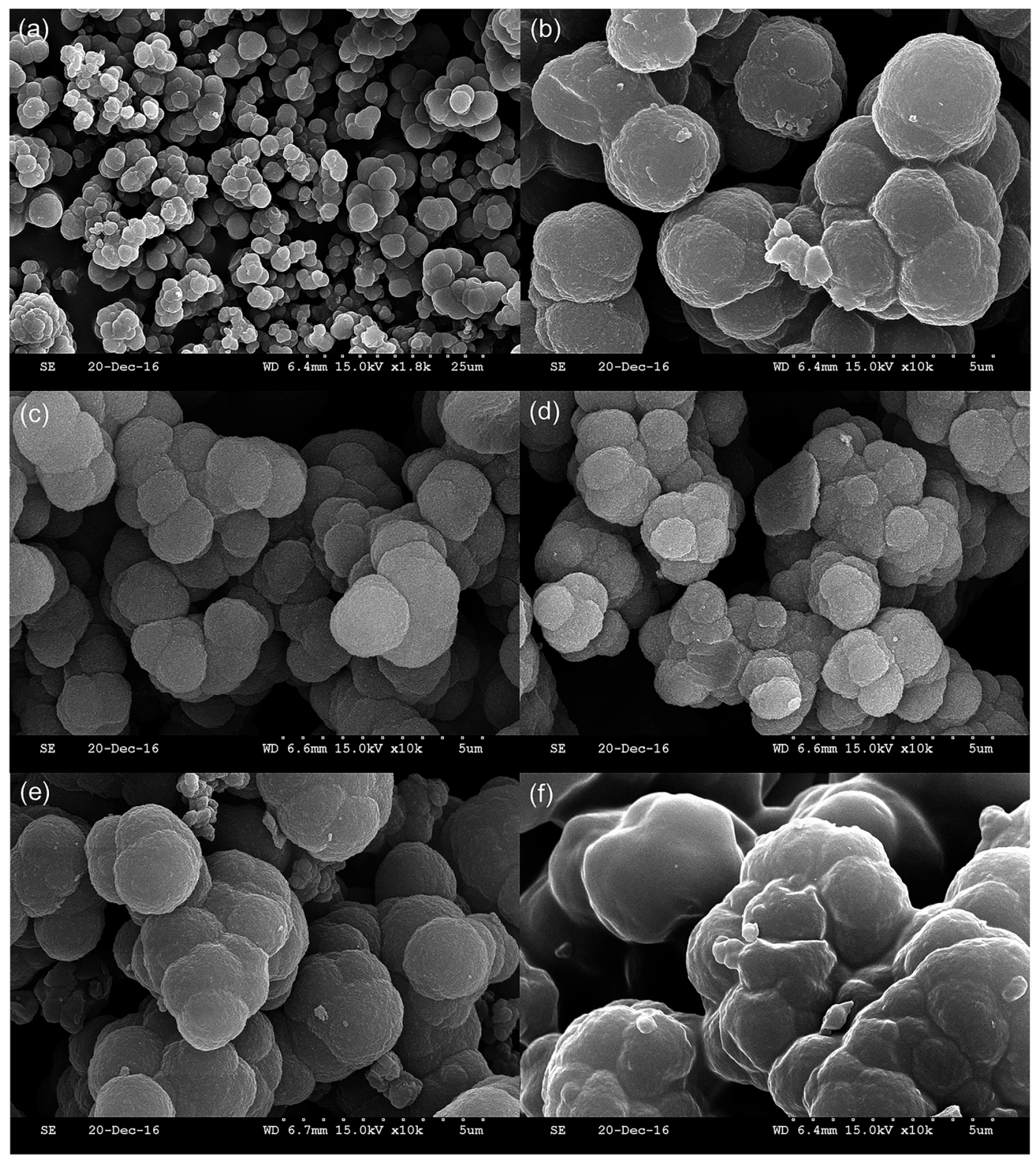

Fig. 5 Scanning electron micrograph of NIP (a) and (b), LMIP (c), DES-LMIP (d), TMIP (e) and DES-TMIP (f).

\subsection{Evaluation of the selective adsorption capacity of materials}

Experiments of static absorption and dynamic adsorption were completed at room temperature to evaluate the binding properties of these materials. Fig. 7a and c shows that the amount of levofloxacin and tetracycline adsorbed by five of the materials increased with increasing concentration (5.0-500 $\left.\mu \mathrm{g} \mathrm{mL} \mathrm{m}^{-1}\right)$. DES-LMIP and DES-TMIP showed the highest affinity in all these materials. The absorption by the other five materials increased until the levofloxacin concentration was $200 \mu \mathrm{g} \mathrm{mL}^{-1}$. The adsorption capacity showed no further change when the concentration was higher than $200 \mu \mathrm{g} \mathrm{mL}^{-1}$. On the other hand, the saturation adsorption concentration of tetracycline was 300 $\mu \mathrm{g} \mathrm{mL} \mathrm{m}^{-1}$. According to Fig. $7 \mathrm{~b}$ and $\mathrm{d}$, the adsorption capacity of these five materials increased with increasing adsorption time before saturation adsorption. These materials required $10 \mathrm{~h}$ to reach adsorption saturation. In five of the materials, DES-MIPs showed the best adsorption capacity; the adsorption capacity of NIPs was lower than DES-MIPs and MIPs.

\subsection{Validation of the SPE-HPLC method}

DES-MIPs was assessed as a SPE sorbent for the purification of levofloxacin and tetracycline, and the method under the optimized protocols was validated. The calibration curves were in the range of $0.1-500.0 \mu \mathrm{g} \mathrm{mL}^{-1}$ for levofloxacin and tetracycline. Table 2 lists the regression equation ( $X$ is peak area; $Y$ is concentration). Based on a signal-to-noise ratio of 3 and 10, the limit of detection (LOD) and limit of quantitation (LOQ) of the method for levofloxacin were $0.01 \mu \mathrm{g} \mathrm{mL} L^{-1}$ and $0.03 \mu \mathrm{g} \mathrm{mL} \mathrm{m}^{-1}$ and tetracycline were $0.04 \mu \mathrm{g} \mathrm{mL}^{-1}$ and $0.05 \mu \mathrm{g} \mathrm{mL} \mathrm{mL}^{-1}$, 


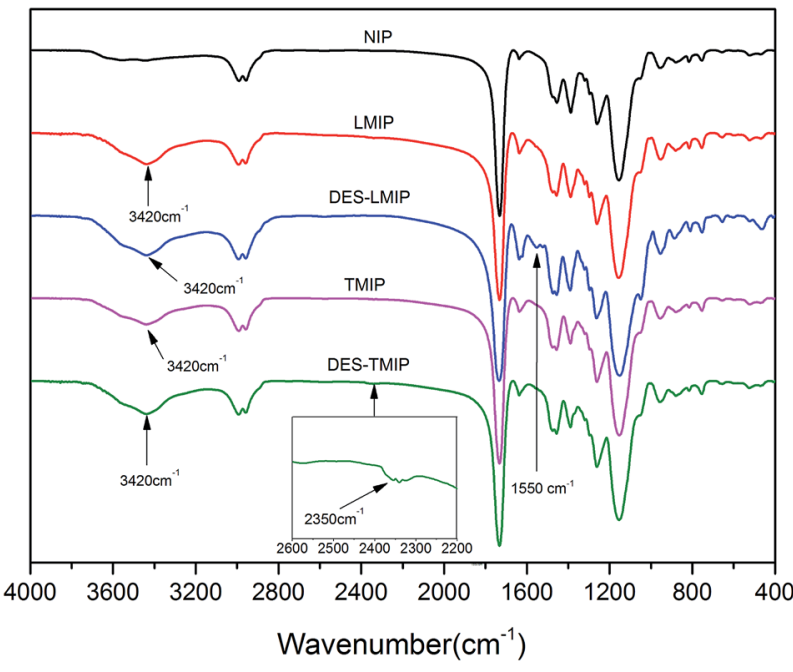

Fig. 6 FT-IR spectrum of materials.

respectively. The precision and accuracy were assessed by analyzing five replicates of spiked samples at three spiked levels on the same day and three separate days $(n=3)$; the intra-assay and inter-assay precision, which is expressed as the relative standard deviation (RSD), were $1.8 \%$ and $1.1 \%$. The method
Table 2 Calibration curves for levofloxacin and tetracycline

\begin{tabular}{lll}
\hline Analytes & Regression equation & $R^{2}$ \\
\hline Levofloxacin & $Y=0.185 X+4.2176$ & 0.9997 \\
Tetracycline & $Y=0.232 X+2.1659$ & 0.9995
\end{tabular}

recoveries ranged from $97.2-100.2 \%$ for levofloxacin with DESLMIP and $95.7-99.2 \%$ for tetracycline with DES-TMIP when the concentrations were 5,25 , and $50 \mu \mathrm{g} \mathrm{mL}^{-1}$ at the three levels, as shown in Table 3. The RSD of levofloxacin and tetracycline from the inter-day and intra-day determinations was less than $1.1 \%$ and $1.8 \%$, respectively.

\subsection{Purification of antibiotics from the millet extract}

The five materials were used to purify antibiotics from a millet extract by SPE. The millet extract was the interferent in this purification work (Fig. 3). All the materials could remove the interferent well, but the recovery of antibiotics was much different. As shown in Fig. 8 and 9, although DES-LMIP (DESTMIP) and LMIP (TMIP) showed good selectivity for levofloxacin (tetracycline), but the selectivity for tetracycline (levofloxacin) was bad. The selectivity of DES-MIPs was much better
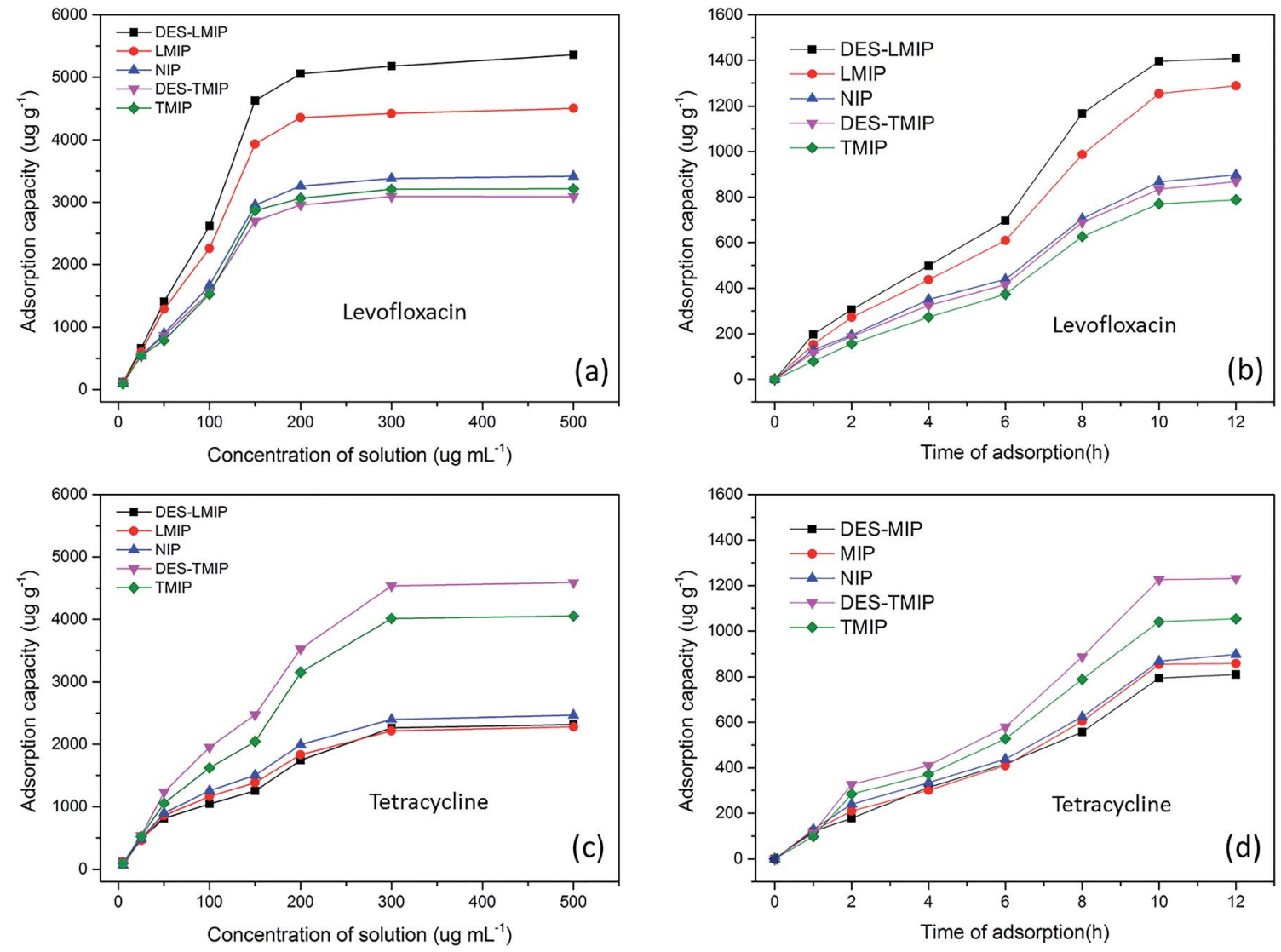

Fig. 7 The static adsorption capacity of the proposed materials for antibiotics (a and c). The dynamic adsorption capacity of the proposed materials for antibiotics ( $b$ and d). Column: C18 $(150 \times 4.6 \mathrm{~mm}$ i.d.), detector: UV $(294 \mathrm{~mm})$, injection volume: $10 \mu \mathrm{L}$, mobile phase: $0.05 \mathrm{M}$ $\mathrm{NaH}_{2} \mathrm{PO}_{4}-\mathrm{ACN}(82: 18 \mathrm{v} / \mathrm{v} \mathrm{pH}=3)$, flow rate: $1 \mathrm{~mL} \mathrm{~min}^{-1}$. 
Table 3 SPE-HPLC method recoveries $(n=3)$ and RSD values of levofloxacin and tetracycline standard solution

\begin{tabular}{|c|c|c|c|c|c|}
\hline \multirow[b]{2}{*}{ Analytes } & \multirow[b]{2}{*}{$\begin{array}{l}\text { Spiked } \\
\left(\mu \mathrm{g} \mathrm{mL}^{-1}\right)\end{array}$} & \multicolumn{2}{|l|}{ Intra-day } & \multicolumn{2}{|l|}{ Inter-day } \\
\hline & & $\begin{array}{l}\text { Recovery } \\
(\%)\end{array}$ & $\begin{array}{l}\text { RSD } \\
(\%)\end{array}$ & $\begin{array}{l}\text { Recovery } \\
(\%)\end{array}$ & $\begin{array}{l}\text { RSD } \\
(\%)\end{array}$ \\
\hline \multirow[t]{3}{*}{ Levofloxacin } & 5 & 99.8 & 0.7 & 98.2 & 1.2 \\
\hline & 25 & 99.5 & 1.4 & 100.2 & 1.6 \\
\hline & 50 & 97.2 & 1.5 & 99.4 & 1.8 \\
\hline \multirow[t]{3}{*}{ Tetracycline } & 5 & 97.8 & 0.3 & 96.9 & 0.7 \\
\hline & 25 & 96.5 & 1.2 & 99.2 & 0.9 \\
\hline & 50 & 98.3 & 1.1 & 95.7 & 1.0 \\
\hline
\end{tabular}

than MIPs. DES-LMIP and DES-TMIP showed the highest selectivity recovery for levofloxacin $(94.5 \%)$ and tetracycline (93.3\%) from millet extract with mixture antibiotics, and could remove the interferent effectively.

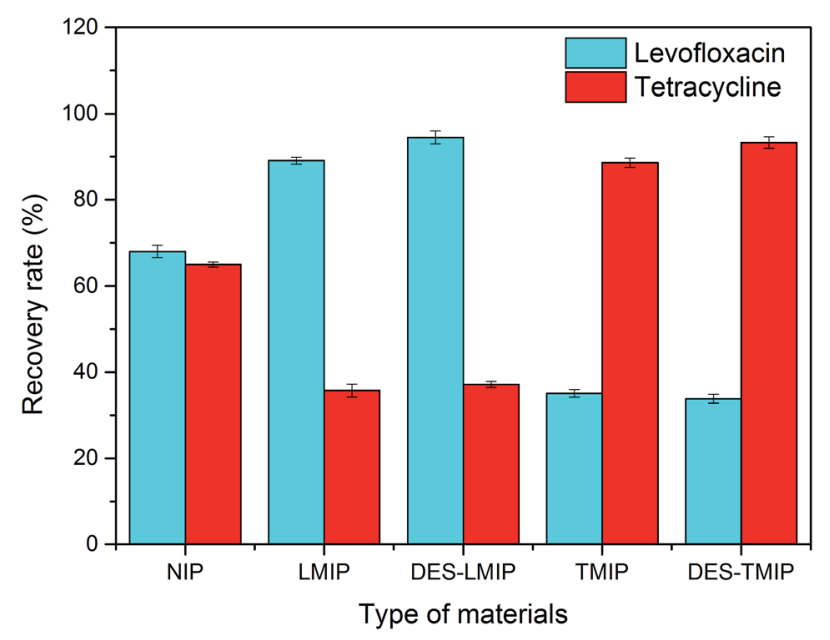

Fig. 8 The recoveries of levofloxacin and tetracycline.

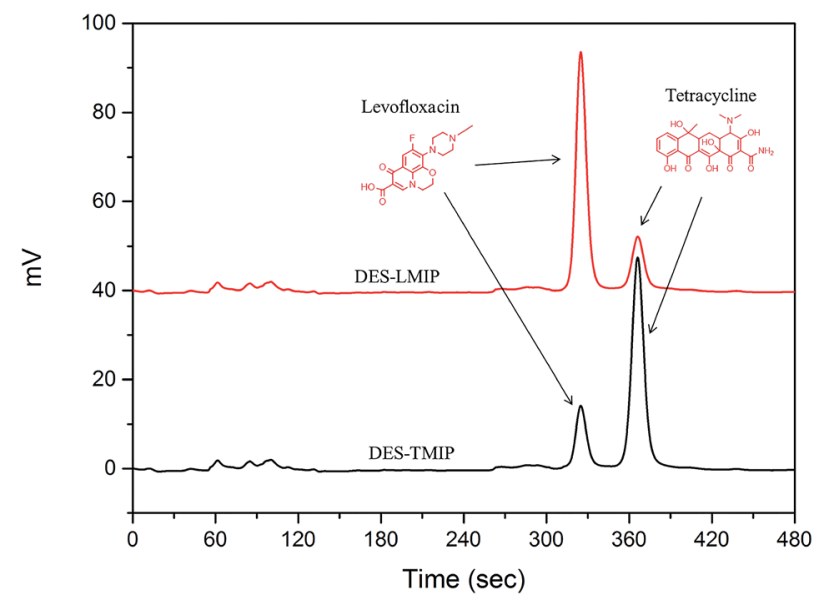

Fig. 9 The chromatograms of levofloxacin $\left(\mathrm{ng} \mathrm{mL}^{-1}\right)$ and tetracycline (ng $\mathrm{mL}^{-1}$ ) in millet extractive after purification by DES-LMIP and DESTMIP. Column: C18 $(150 \times 4.6 \mathrm{~mm}$ i.d. $)$, detector: UV $(294 \mathrm{~mm})$, injection volume: $10 \mu \mathrm{L}$, mobile phase: $0.05 \mathrm{M} \mathrm{NaH}_{2} \mathrm{PO}_{4}-\mathrm{ACN}$ (82 : 18

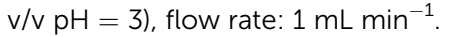

\section{Conclusions}

DES-LMIP and DES-TMIP were modified by betaine-based DES. These materials were applied for SPE packing and characterized by FE-SEM and FT-IR. The adsorption curves of the DES-based MIPs exhibited better molecular recognition ability and binding ability for levofloxacin and tetracycline than the conventional MIP. The method recoveries ranged from 97.2$100.2 \%$ for levofloxacin with DES-LMIP and $95.7-99.2 \%$ for tetracycline with DES-TMIP. The selective adsorption of the DES-based MIPs was also better than the conventional materials. DES-LMIP and DES-TMIP showed the highest selectivity recovery for levofloxacin $(94.5 \%)$ and tetracycline $(93.3 \%)$ from millet extract with mixture antibiotics, and could remove the interferent effectively. Overall, DES can potentially be extended to a broad scope of effective drug screening efforts in clinical laboratories.

\section{Acknowledgements}

This research was supported by Basic Science Research Program through the National Research Foundation of Korea (NRF) funded by the Ministry of Education (NRF-2015R1A4A1042434).

\section{References}

$1 \mathrm{X}$. Li and K. H. Row, Development of deep eutectic solvents applied in extraction and separation, J. Sep. Sci., 2016, 39, 3505-3520.

2 B. Tang and K. H. Row, Recent developments in deep eutectic solvents in chemical sciences, Monatsh. Chem., 2013, 144, 1427-1454.

$3 \mathrm{X}$. Li and K. H. Row, Exploration of mesoporous stationary phases prepared using deep eutectic solvents combining choline chloride with 1,2-butanediol or glycerol for use in size-exclusion chromatography, Chromatographia, 2015, 78, 1321-1325.

4 A. P. Abbott, G. Capper, D. L. Davies, et al., Novel solvent properties of choline chloride/urea mixtures, Chem. Commun., 2003, 70-71.

5 A. P. Abbott, G. Capper and S. Gray, Design of improved deep eutectic solvents using hole theory, ChemPhysChem, 2006, 7, 803-806.

6 M. R. Jo, H. J. Lee, T. S. Lee, et al., Simultaneous determination of macrolide residues in fish and shrimp by liquid chromatography-tandem mass spectrometry, Food Sci. Biotechnol., 2011, 20, 823-827.

7 A. L. Demain, Pharmaceutically active secondary metabolites of microorganisms, Appl. Microbiol. Biotechnol., 1999, 52, 455-463.

8 M. Francisco, A. van den Bruinhorst and M. C. Kroon, Lowtransition-temperature mixtures (LTTMs): a new generation of designer solvents, Angew. Chem., Int. Ed., 2013, 52, 30743085.

9 Y. Han, S. S. Lee and J. Y. Ying, Siliceous mesocellular foam for high-performance liquid chromatography: effect of 
morphology and pore structure, J. Chromatogr. A, 2010, 1217, 4337-4343.

10 G. Li, W. Wang, Q. Wang, et al., Deep eutectic solvents modified molecular imprinted polymers for optimized purification of chlorogenic acid from honeysuckle, $J$. Chromatogr. Sci., 2016, 54, 271-279.

11 X. Li, Y. R. Lee and K. H. Row, Synthesis of mesoporous siliceous materials in choline chloride deep eutectic solvents and the application of these materials to highperformance size exclusion chromatography, Chromatographia, 2016, 79, 375-382.

12 Q. Cui, X. Peng, X. H. Yao, et al., Deep eutectic solvent-based microwave-assisted extraction of genistin, genistein and apigenin from pigeon pea roots, Sep. Purif. Technol., 2015, 150, 63-72.

13 Y. Kumar, P. Singh and G. Bhargava, Recent developments in the synthesis of condensed $\beta$-lactams, RSC Adv., 2016, 6, 99220-99250.

14 X. Lei, C. Gong, Y. Li, et al., Influence of the acetamide from acetonitrile hydrolysis in acid-contained mobile phase on the ultraviolet detection in high performance liquid chromatography, Chromatographia, 2016, 79, 1257-1262.

15 S. Ma, X. Ye, P. Huang, et al., Simultaneous determination of nitroimidazoles and amphenicol antibiotics in water samples using ultrasound-assisted dispersive liquid-liquid microextraction coupled with ultra-high-performance liquid chromatography with tandem mass spectrometry, Anal. Methods, 2016, 8, 8219-8226.

16 Z. Yang, Q. Cai, N. Chen, et al., Selective separation and identification of metabolite groups of Polygonum cuspidatum extract in rat plasma using dispersion solidphase extraction by magnetic molecularly imprinted polymers coupled with LC/Q-TOF-MS, RSC Adv., 2016, 6, 12193-12204.

17 S. J. Lehotay, L. Han and Y. Sapozhnikova, Automated minicolumn solid-phase extraction cleanup for high-throughput analysis of chemical contaminants in foods by low-pressure gas chromatography-tandem mass spectrometry, Chromatographia, 2016, 79, 1113-1130.

18 C. I. Kang, J. H. Song, S. H. Kim, et al., Risk factors for levofloxacin-nonsusceptible Streptococcus pneumoniae in community-acquired pneumococcal pneumonia: a nested case-control study, Eur. J. Clin. Microbiol. Infect. Dis., 2014, 33, 55-59.

19 T. Kemmei, S. Kodama, H. Fujishima, et al., Determination of ethylenediaminetetraacetic acid in sea water by solidphase extraction and high-performance liquid chromatography, Anal. Chim. Acta, 2012, 709, 54-58.

20 M. Sillanp, J. Sorvari and M. L. Sihvonen, Low-level determination of EDTA and DTPA in natural waters by gas chromatography, Chromatographia, 1996, 42, 578-582.
21 S. Dong, Z. Yan and H. Yang, A sensitive precolumn derivatization method for determination of piperazine in vortioxetine hydrobromide using a C8 column and highperformance liquid chromatography-mass spectrometry, Anal. Sci., 2016, 32, 1333-1338.

22 T. Zhu, S. Li and K. H. Row, Molecularly imprinted monolithic material for the extraction of three organic acids from Salicornia herbacea L., J. Appl. Polym. Sci., 2011, 121, 1691-1696.

23 M. Zhao, G. Li, W. Kong, et al., Convenient and sensitive HPLC method for determination of nitrosamines in foodstuffs based on pre-column fluorescence labeling, Chromatographia, 2016, 79, 431-439.

24 H. Yan, M. Wang, Y. Han, et al., Hybrid molecularly imprinted polymers synthesized with 3aminopropyltriethoxysilane-methacrylic acid monomer for miniaturized solid-phase extraction: a new and economical sample preparation strategy for determination of acyclovir in urine, J. Chromatogr. A, 2014, 1346, 16-24.

25 I. A. Nicholls, O. Ramstrom and K. Mosbach, Insights into the role of the hydrogen bond and hydrophobic effect on recognition in molecularly imprinted polymer synthetic peptide receptor mimics, J. Chromatogr. A, 1995, 691, 349353.

26 T. Muhammad, L. Cui, W. Jide, et al., Rational design and synthesis of water-compatible molecularly imprinted polymers for selective solid phase extraction of amiodarone, Anal. Chim. Acta, 2012, 709, 98-104.

27 N. Liang, P. Huang, X. Hou, et al., Solid-phase extraction in combination with dispersive liquid-liquid microextraction and ultra-high performance liquid chromatographytandem mass spectrometry analysis: the ultra-trace determination of 10 antibiotics in water samples, Anal. Bioanal. Chem., 2016, 408, 1701-1713.

$28 \mathrm{X} . \mathrm{Hu}, \mathrm{Q}$. Cai, Y. Fan, et al., Molecularly imprinted polymer coated solid-phase microextraction fibers for determination of Sudan I-IV dyes in hot chili powder and poultry feed samples, J. Chromatogr. A, 2012, 1219, 39-46.

29 P. Spégel, L. Schweitz and S. Nilsson, Molecularly imprinted polymers, Anal. Bioanal. Chem., 2002, 372, 37-38.

30 G. Li, W. S. Ahn and K. H. Row, Hybrid molecularly imprinted polymers modified by deep eutectic solvents and ionic liquids with three templates for the rapid simultaneous purification of rutin, scoparone, and quercetin from Herba Artemisiae Scopariae, J. Sep. Sci., 2016, 39, 4465-4473.

31 W. Tang, G. Li, K. H. Row, et al., Preparation of hybrid molecularly imprinted polymer with double templates for rapid simultaneous purification of theophylline and chlorogenic acid in green tea, Talanta, 2016, 152, 1-8. 